\title{
COMPARISON OF ENERGY FLOW STREAM AND ISENTROPIC METHOD FOR STEAM TURBINE ENERGY ANALYSIS
}

\author{
Sebastijan Blažević*, Vedran Mrzluak, Nikola AnĐelić, Zlatan Car \\ University of Rijeka, Faculty of Engineering, Vukovarska 58, Rijeka, Croatia \\ * corresponding author: sblazevic@riteh.hr
}

\begin{abstract}
In this paper, a comparison of two different methods for a steam turbine energy analysis is presented. A high-pressure steam turbine from a supercritical thermal power plant (HPT) was analysed at three different turbine loads using the energy flow stream (EFS) method and isentropic (IS) method. The EFS method is based on steam turbine input and output energy flow streams and on the real steam turbine produced power. The method is highly dependable on the steam mass flow rate lost through the turbine gland seals. The IS method is based on a comparison of turbine steam expansion processes. Observed energy analysis methods cannot be directly compared because they are based on different sources of steam turbine energy losses, so, an overall steam turbine energy analysis is presented. Unlike most steam turbines from the literature, the analysed HPT did not have the highest overall energy efficiency at a full load due to exceeding the water/steam critical pressure at the turbine inlet during such operation.
\end{abstract}

KEYwORDS: Steam turbine, energy analysis, energy flow method, isentropic method.

\section{INTRODUCTION}

The scientific and professional literature offers many different energy and numerical analysis of entire steam power plants as presented by Erdem et al. [1, Mitrović et al. 22, Kumar et al. [3, Noroozian et al. 4], Ahmadi and Toghraie [5] and Uysal et al. [6]. The energy and numerical analysis can also be applied to a research of steam power plant components, such as steam turbines [7], [8], steam condensers [9], steam generators [10, 11] and air heaters for steam generators 12, feed water heaters 13, gland steam condensers [14] and many others. An investigation of combined power plants [15], CHP (Combined Heat and Power) plants [16], solar power plants [17] or power plants, which use solar assisting [18, can also be performed by various types of energy analysis methods.

Along with the energy, an exergy analysis of various power plants: solid fuel-fired [19], CHP [20, multigeneration [21], steam supercritical [22] and nuclear [23, which takes into account the ambient state (temperature and pressure of the ambient) in which power plant and all of the plant's components operate, is widely used nowadays.

Energy and exergy analyses are also commonly used for the efficiencies and losses research of marine propulsion systems [24] and power plants [25], components of such systems [26, 27] or the entire complex energy systems on the cruise ships [28], container ships [29] or chemical tankers [30]. A several industrial plants can also be evaluated and optimized by using energy and exergy analyses, such as a sugar factory [31, milk powder production system [32, milk processing factory [33] and industrial-scale yogurt production plant 34.
An energy analysis of some power plant components will result in energy power losses equal to zero and energy efficiency equal to $100 \%$. For such components, a specific enthalpy of the operating medium at component inlet and outlet remains constant (change in the operating medium specific enthalpy can be neglected). For such components, the only relevant analysis is the exergy analysis. Pressure reduction valves (throttle valves) [35, 36] and steam turbine labyrinth seals [37. are the best examples of such components.

The most complex analyses of power plants and its components are 3E (Energy, Exergy and Economic/ Environmental) [38, 39] and 4E (Energy, Exergy, Economic and Environmental) [40, 41] analyses, which provide a complete insight into a power plant operation from various aspects. Such analyses are often used for power plant optimization and research of the pollutants reduction possibilities [42, 43]. A critical review of $4 \mathrm{E}$ analysis for a various power plants can be found in [44].

An essential element of any steam power plant energy analysis is the main steam turbine with all of its cylinders 45. Such analysis usually does not take into account the flow details within the turbine [46] or other steam turbine inner details.

In scientific literature, two methods of the steam turbine energy analysis are presented. The first method is an energy flow stream method, which is based on the turbine input and output energy streams and real turbine developed power. The results of the energy flow stream method can be found in [5, 47]. In order to calculate the steam turbine energy power loss and energy efficiency by using the energy flow stream method, the authors presented data of steam mass flow rates lost through each turbine gland seal (or 
cumulative steam mass flow rate lost through both turbine gland seals).

The second method for steam turbine energy analysis is the isentropic method and the results of the steam turbine energy analysis using this method can be found in [48, 49]. The isentropic energy analysis method is based on a comparison of turbine steam expansion processes - ideal (isentropic) and real (polytropic) [50. In an isentropic energy analysis of a steam turbine, the authors do not present the data of steam mass flow rates lost through turbine gland seals [51] (in some situations, cumulative steam mass flow rate lost through both turbine gland seals is neglected because it is approximately $1 \%$ of the steam mass flow rate at the turbine inlet). The usage of the energy flow stream method for the energy analysis of a steam turbine in such situations will result with turbine energy power loss equal to zero, while the energy efficiency of the steam turbine will be equal to $100 \%$. Without data (or neglecting) regarding steam mass flow rates lost through turbine gland seals, the isentropic method is the only relevant method for the energy analysis of any steam turbine.

As the authors of this paper, so far, did not found a comparison of the energy flow stream and isentropic method for the energy analysis of any steam turbine in any literature, in this paper, there is an energy analysis of a high pressure steam turbine (HPT) from a supercritical thermal power plant [52] with both energy analysis methods presented. The HPT is analysed at three different turbine loads in order to obtain a complete insight into results of both energy analysis methods. Obtained results were compared and discussed. The main conclusion obtained from the performed analysis is that the results of the energy flow stream method and isentropic method cannot be directly compared because each method presents a different cause of steam turbine energy losses (and consequently different energy efficiencies). Overall, the HPT energy analysis, which represents a combination of steam turbine energy power losses and energy efficiencies obtained by both of observed methods, is presented. An overall energy analysis of any steam turbine (not only of the researched HPT) completely defines the steam turbine energy power losses and energy efficiencies.

\section{High PRESSURE STEAM TURBine FROM SUPERCRITICAL THERMAL POWER PLANT}

\subsection{General ENERGy ANALYSis EQUATIONS}

An energy analysis, in general, is defined by the first law of thermodynamics [53]. Mass and energy balance equations for a standard volume in a steady state disregarding potential and kinetic energy are defined according to [54]:

$$
\sum \dot{m}_{I N}=\sum \dot{m}_{O U T}
$$

$$
\sum \dot{m}_{I N} \cdot h_{I N}-\sum \dot{m}_{O U T} \cdot h_{O U T}=P-\dot{Q}
$$

The energy power of a flow for any fluid stream can be calculated by using the equation [55]:

$$
\dot{E}_{e n}=\dot{m} \cdot h .
$$

The energy efficiency may take different forms and types, which are dependable on the analysed component (control volume) or system. Usually, energy efficiency can be written, according to [56] as:

$$
\eta_{\text {en }}=\frac{\text { Energy output }}{\text { Energy input }}
$$

\subsection{High PRESSURE STEAM TURBine (HPT) ENERGY ANALYSIS}

The scheme and steam flow marks of the analysed high pressure steam turbine (HPT) from a supercritical thermal power plant are presented in Fig. 11 The analysed steam turbine has one steam flow inlet, two steam flow extractions and one steam flow outlet. The second steam extraction (point 3 in Fig. 1) is positioned near a steam turbine outlet, therefore, the steam operating parameters (pressure and temperature) at the second steam extraction are equal to the steam operating parameters on the HPT outlet (steam generator inlet on re-heat, point 4 in Fig. 1).

The analysis of steam mass flow rates lost through the front and rear gland seal requires introducing two additional operating points (points $\mathrm{x}$ and $\mathrm{y}$ in Fig. 1). In the operating point $\mathrm{x}$ - the steam has an identical temperature and pressure as the steam at the turbine inlet (point 1 in Fig. 1) and as the steam lost through the front gland seal. The steam mass flow rate in the operating point $\mathrm{x}$ expand through the HPT. In the operating point $\mathrm{y}$ - the steam has an identical temperature and pressure as the steam at the turbine outlet and as the steam lost through the rear gland seal. The steam mass flow rate in operating point $\mathrm{y}$ is the steam mass flow rate at the end of the expansion process (after the second steam extraction).

The steam mass flow rate lost through the front gland seal $(1-\mathrm{x})$ is the difference of the steam mass flow rates at the turbine inlet (point 1 in Fig. 1) and at the beginning of the expansion process (point $\mathrm{x}$ in Fig. 1), while the steam mass flow rate lost through the rear gland seal $(y-4)$ is the difference of the steam mass flow rates at the end of the expansion process (after second steam extraction - point y in Fig. 1) and at the turbine outlet (point 4 in Fig. 1).

The required steam specific enthalpies and specific entropies in both the HPT energy analysis methods and in all turbine operating points were calculated from the known pressure and temperature of each flow stream by using Nist REFPROP 9.0 software [57]. 


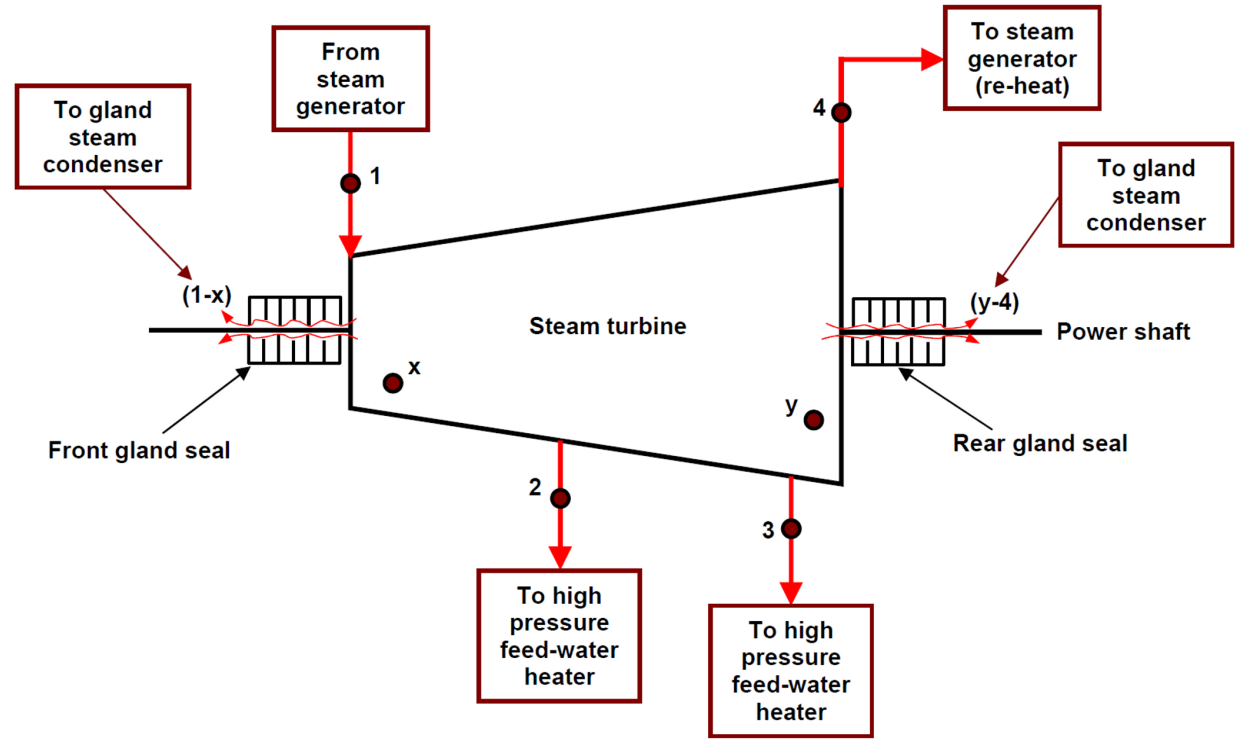

FiguRE 1. Scheme of the analysed high pressure steam turbine (HPT) along with steam flow stream marks.

\subsubsection{ENERGY FLOW STREAM METHOD}

The energy flow stream method for the HPT (or any other steam turbine) energy analysis is based on turbine input and output energy flow streams (along with the real steam turbine developed power). This method is highly dependable on a steam mass flow rate lost through the turbine gland seals and that the lost steam mass flow rate (for both front and rear gland seal) is the essential component, which defines the steam turbine energy power loss.

According to Fig. 1 , the HPT energy flow stream analysis equations (which define energy power loss and energy efficiency) are as follows:

- Steam turbine real (polytropic) developed power:

$$
P_{R E}=\dot{m}_{x} \cdot\left(h_{1}-h_{2}\right)+\left(\dot{m}_{x}-\dot{m}_{2}\right) \cdot\left(h_{2}-h_{3}\right),
$$

where:

$$
\begin{gathered}
\dot{m}_{x}=\dot{m}_{1}-\dot{m}_{(1-x)}=\dot{m}_{2}+\dot{m}_{3}+\dot{m}_{y} \\
h_{1}=h_{(1-x)}=h_{x} .
\end{gathered}
$$

- HPT energy power input:

$$
\dot{E}_{e n, I N, E F S}=\dot{E}_{e n, 1}=\dot{m}_{1} \cdot h_{1} .
$$

- HPT energy power output:

$$
\begin{array}{r}
\dot{E}_{e n, O U T, E F S}=\dot{E}_{e n, 2}+\dot{E}_{e n, 3}+\dot{E}_{e n, 4}+P_{R E} \\
=\dot{m}_{2} \cdot h_{2}+\dot{m}_{3} \cdot h_{3}+\dot{m}_{4} \cdot h_{4}+P_{R E},
\end{array}
$$

where:

$$
h_{3}=h_{y}=h_{y-4}=h_{4} .
$$

- Cumulative steam mass flow rate lost through both the HPT gland seals (front and rear):

$$
\begin{array}{r}
\dot{m}_{\text {lost }, \text { cumulative }}=\dot{m}_{1}-\dot{m}_{2}-\dot{m}_{3}-\dot{m}_{4}= \\
\dot{m}_{(1-x)}+\dot{m}_{(y-4)} .
\end{array}
$$

- Cumulative steam mass flow rate lost through both the HPT gland seals can be distributed on the steam mass flow rate lost through the front gland seal:

$$
\dot{m}_{(1-x)}=\dot{m}_{\text {lost }, \text { cumulative }} \cdot z_{\text {front }}(\%) \text {, }
$$

and on a steam mass flow rate lost through the rear gland seal:

$$
\dot{m}_{(y-4)}=\dot{m}_{\text {lost }, \text { cumulative }} \cdot z_{\text {rear }}(\%) .
$$

In equations $(12)$ and $(13), z_{\text {front }}(\%)$ and $z_{\text {rear }}(\%)$ represents the percentages of $\dot{m}_{\text {lost,cumulative, which }}$ is lost through the front and rear gland seal. The steam, which passes through the front gland seal has the same specific enthalpy as the steam at the turbine inlet (point 1 in Fig. 1), while the steam, which passes through rear gland seal, has the same specific enthalpy as the steam at the turbine outlet (point 4 in Fig. 1), as declared in [58].

- HPT energy power loss:

$$
\begin{gathered}
\dot{E}_{e n, P L, E F S}=\dot{E}_{e n, I N, E F S}-\dot{E}_{e n, O U T, E F S}= \\
\dot{m}_{1} \cdot h_{1}-\dot{m}_{2} \cdot h_{2}-\dot{m}_{3} \cdot h_{3}-\dot{m}_{4} \cdot h_{4}-P_{R E}= \\
\dot{m}_{(1-x)} \cdot h_{1}+\dot{m}_{(y-4)} \cdot h_{4} .
\end{gathered}
$$

- HPT energy efficiency:

$$
\begin{aligned}
& \eta_{e n, E F S}=\frac{P_{R E}}{\dot{E}_{e n, 1}-\dot{E}_{e n, 2}-\dot{E}_{e n, 3}-\dot{E}_{e n, 4}} \\
& =\frac{\dot{m}_{x} \cdot\left(h_{1}-h_{2}\right)+\left(\dot{m}_{x}-\dot{m}_{2}\right) \cdot\left(h_{2}-h_{3}\right)}{\dot{m}_{1} \cdot h_{1}-\dot{m}_{2} \cdot h_{2}-\dot{m}_{3} \cdot h_{3}-\dot{m}_{4} \cdot h_{4}} .
\end{aligned}
$$

During the usage of the energy flow stream method, it is important not to include the steam mass flow rates lost through the turbine front and rear gland seal in the equation for the energy power output (9) and into the equation for the energy efficiency (15). In the 


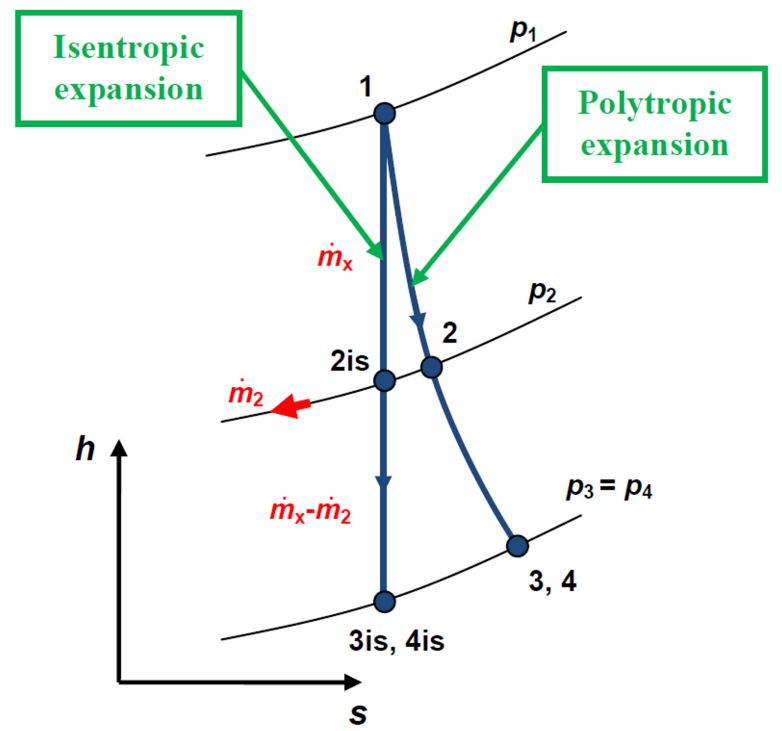

Figure 2. Comparison of isentropic and polytropic steam expansion processes for the analysed HPT.

literature, it can be found that some authors include this steam mass flow rates (multiplied with steam specific enthalpies) into the equations for the energy power output and energy efficiency. The result is that the energy power input and output becomes the same, which further resulted in a turbine energy power loss equal to zero, the equation (14), and turbine energy efficiency is then equal to $100 \%$, equation (15).

\subsubsection{ISENTROPIC METHOD}

The isentropic steam turbine energy analysis method is based on a comparison of turbine steam expansion processes [59]. The real turbine steam expansion process is polytropic and according to this steam expansion, equation (5), the real HPT developed power is defined. An ideal steam turbine expansion is isentropic, because this expansion assumes that the steam specific entropy remains constant throughout the whole HPT process. A comparison of ideal (isentropic) and real (polytropic) steam expansion processes for the analysed HPT are presented in Fig. 2, according to steam flow streams, Fig. 1] The main equations of the HPT energy analysis by using isentropic method are:

- Steam entropy on the isentropic expansion line (according to Fig. 2):

$$
s_{1}=s_{2 i s}=s_{3 i s}=s_{4 i s} .
$$

- HPT ideal (isentropic) developed power:

$$
P_{I S}=\dot{m}_{x} \cdot\left(h_{1}-h_{2 i s}\right)+\left(\dot{m}_{x}-\dot{m}_{2}\right) \cdot\left(h_{2 i s}-h_{3 i s}\right) .
$$

HPT real (polytropic) developed power is calculated according to equation (5).

- HPT energy power loss:

$$
\dot{E}_{e n, P L, I S}=P_{I S}-P_{R E} .
$$

- HPT energy efficiency:

$$
\begin{aligned}
& \eta_{e n, I S}=\frac{P_{R E}}{P_{I S}} \\
= & \frac{\dot{m}_{x} \cdot\left(h_{1}-h_{2}\right)+\left(\dot{m}_{x}-\dot{m}_{2}\right) \cdot\left(h_{2}-h_{3}\right)}{\dot{m}_{x} \cdot\left(h_{1}-h_{2 i s}\right)+\left(\dot{m}_{x}-\dot{m}_{2}\right) \cdot\left(h_{2 i s}-h_{3 i s}\right)} .
\end{aligned}
$$

\section{Operating parameters of the ANALYSED HPT AT THREE DIFFERENT LOADS}

The HPT operating parameters for all steam flow streams, Fig. 1] were found in [52 and presented in Table1. Specific enthalpies, isentropic specific enthalpies and specific entropies of all steam flow streams are calculated with Nist REFPROP 9.0 software [57].

In Table 1, specific exergies of each steam flow stream are also presented. As specific exergy is dependable on the conditions of the ambient in which the analysed turbine operates, specific exergies presented in Table 1 are calculated for the ambient pressure of 1 bar $(0.1 \mathrm{MPa})$ and ambient temperature of 25 ${ }^{\circ} \mathrm{C}(298 \mathrm{~K})$, as proposed in 60. By using specific exergies, the exergy analysis of the researched HPT can be performed at each load. The specific exergy of each steam flow stream is also calculated with Nist REFPROP 9.0 software [57].

The analysed high pressure steam turbine is an integral part of supercritical thermal power plant process with a maximum power of $660 \mathrm{MW}$ (entire power plant power, not only the HPT) at the highest load. Authors in [52] analysed the complete power plant process, under constant and pure sliding pressure operation at three different loads (loads of $60 \%, 80 \%$ and full load of $100 \%$ ).

As presented in Table 1, the cumulative steam mass flow rate lost through both the turbine gland seals is known while the steam mass flow rate lost through each HPT gland seal is not known. According to the equations (11), (12) and (13), the steam mass flow rate lost through both HPT gland seals can be distributed on each gland seal in different percentage ratios. Such distribution will surely influence the steam turbine energy analysis (not only researched, but also any other steam turbine energy analysis), regardless of used energy analysis method.

The HPT gland seal distribution from Table 2 is researched. It should be noted that the first and the last combination (No.1 and No.11) are not usual combinations, which can be expected during the HPT operation, because certain steam mass flow rate will surely be lost through both (front and rear) gland seals, but such combinations can be researched numerically. For each combination from Table 2 both steam turbine energy analysis methods (energy flow stream method and isentropic method) at each observed HPT load (load of $60 \%, 80 \%$ and full load of $100 \%$ ) were performed. 


\begin{tabular}{|c|c|c|c|c|c|c|c|}
\hline $\begin{array}{l}\text { Stream } \\
\text { flow } \\
\text { (Fig. } 1 \text { ) }\end{array}$ & $\begin{array}{l}\text { Mass } \\
\text { flow } \\
\text { rate } \\
\mathrm{kg} / \mathrm{s}\end{array}$ & $\begin{array}{c}\text { Temperature } \\
\text { K }\end{array}$ & $\begin{array}{c}\text { Pressure } \\
\text { bar }\end{array}$ & $\begin{array}{c}\text { Specific } \\
\text { enthalpy } \\
\text { kJ/kg }\end{array}$ & $\begin{array}{c}\text { Specific } \\
\text { entropy } \\
\mathrm{kJ} /(\mathrm{kg} \cdot \mathrm{K})\end{array}$ & $\begin{array}{c}\text { Specific } \\
\text { exergy } \\
\mathrm{kJ} / \mathrm{kg}\end{array}$ & $\begin{array}{c}\text { Specific } \\
\text { enthalpy- } \\
\text { isentropic } \\
\mathrm{kJ} / \mathrm{kg}\end{array}$ \\
\hline \multicolumn{8}{|c|}{ HPT load $60 \%$} \\
\hline 1 & 327.60 & 766.5 & 138.10 & 3307.7 & 63.775 & 1411 & 3307.7 \\
\hline 2 & 17.63 & 584.7 & 42.32 & 2986.4 & 63.833 & 1088 & 2983.0 \\
\hline 3 & 24.26 & 537.4 & 28.68 & 2904.3 & 63.979 & 1001 & 2893.4 \\
\hline 4 & 281.80 & 537.4 & 28.68 & 2904.3 & 63.979 & 1001 & 2893.4 \\
\hline \multicolumn{8}{|c|}{ HPT load $80 \%$} \\
\hline 1 & 435.70 & 787.0 & 183.00 & 3308.3 & 62.652 & 1445 & 3308.3 \\
\hline 2 & 27.02 & 599.5 & 55.51 & 2987.8 & 62.753 & 1121 & 2981.7 \\
\hline 3 & 35.52 & 550.0 & 37.36 & 2904.4 & 62.896 & 1034 & 2891.0 \\
\hline 4 & 368.70 & 550.0 & 37.36 & 2904.4 & 62.896 & 1034 & 2891.0 \\
\hline \multicolumn{8}{|c|}{ HPT load $100 \%$} \\
\hline 1 & 562.20 & 805.1 & 229.20 & 3306.0 & 61.743 & 1470 & 3306.0 \\
\hline 2 & 40.78 & 625.6 & 71.02 & 3021.6 & 62.322 & 1168 & 2985.7 \\
\hline 3 & 49.21 & 571.9 & 47.07 & 2932.8 & 62.475 & 1075 & 2891.4 \\
\hline 4 & 467.00 & 571.9 & 47.07 & 2932.8 & 62.475 & 1075 & 2891.4 \\
\hline
\end{tabular}

Cumulative steam mass flow rate lost through both gland seals $(\mathrm{kg} / \mathrm{s})$ - load $60 \% ; 80 \% ; 100 \%$

$3.91 ; 4.46 ; 5.21$

Share of cumulative steam mass flow rate lost through both

gland seals in the steam mass flow rate

at the HPT inlet (\%) - load $60 \% ; 80 \% ; 100 \%$

TABLE 1. Steam flow data for the analysed HPT at all observed loads [52].

\begin{tabular}{|c|c|c|}
\hline \multicolumn{3}{|c|}{$\begin{array}{l}\text { Percentage distribution of cumulative steam } \\
\text { mass flow rate lost through both gland seals }\end{array}$} \\
\hline $\begin{array}{l}\text { Combination } \\
\text { number }\end{array}$ & $\begin{array}{l}\text { Front gland } \\
\text { seal }\end{array}$ & $\begin{array}{l}\text { Rear gland } \\
\text { seal }\end{array}$ \\
\hline No.1 & $100 \%$ & $0 \%$ \\
\hline No.2 & $90 \%$ & $10 \%$ \\
\hline No.3 & $80 \%$ & $20 \%$ \\
\hline No.4 & $70 \%$ & $30 \%$ \\
\hline No.5 & $60 \%$ & $40 \%$ \\
\hline No.6 & $50 \%$ & $50 \%$ \\
\hline No.7 & $40 \%$ & $60 \%$ \\
\hline No.8 & $30 \%$ & $70 \%$ \\
\hline No.9 & $20 \%$ & $80 \%$ \\
\hline No.10 & $10 \%$ & $90 \%$ \\
\hline No.11 & $0 \%$ & $100 \%$ \\
\hline
\end{tabular}

TABLE 2. Distribution of HPT cumulative steam mass flow rate lost through both gland seals - researched combinations.

Steam mass flow rates extracted from the HPT (stream flows 2 and 3 in Fig. 1 remains the same at each turbine load as presented in Table 1 regardless of the lost steam mass flow rate distribution.

\section{VALIDATION}

In order to ensure that all operating parameters of each steam flow stream and that for each HPT load they are calculated correctly, the data presented in Table 1 need to be validated. The steam temperature, pressure and mass flow rate of each flow stream were found in [52]. The authors in [52] analysed the whole supercritical steam power plant from the energy and exergy aspect and they assumed, for each turbine cylinder (as well as for the HPT) at each load, that the energy power loss is equal to zero and that energy efficiency is equal to $100 \%$.

From the above, it can be concluded that the HPT analysed in this paper cannot be compared with the results from [52] on the basis of the energy power loss or energy efficiency regardless of used energy analysis method. The parameter, on which a comparison of calculated results can be performed is the HPT real developed power at each turbine load. A good match in the HPT real developed power will confirm the proper calculation of steam specific enthalpies as well as other steam parameters.

For a validation purposes, the HPT real developed power is calculated using equation (5), with a note that the steam mass flow rate lost through both turbine gland seals is calculated as it would be lost only on the rear gland seal (No.11 in Table 2), which was the calculation procedure in $[52$. The compared re- 


\begin{tabular}{lccc}
\hline Turbine load & $60 \%$ & $80 \%$ & $100 \%$ \\
\hline HPT power (MW) & 130.9 & 173.7 & 206.1 \\
This analysis (MW) & 130.71 & 173.73 & 206.19 \\
Difference (\%) & -0.148 & 0.015 & 0.045 \\
\hline
\end{tabular}

TABLE 3. Comparison of calculated HPT real developed power from 52 and by this analysis.

sults of the calculated HPT real developed power are presented in Table 3

It can be seen from Table 3 that the difference in the calculated HPT real developed power between 52 and this analysis is in the range of $\pm 0.15 \%$ for all observed turbine loads. This fact proves that all of steam operating parameters, in each analysed turbine operating point, Fig. 1] are correctly calculated.

\section{Calculation Results of two PRESENTED HPT ENERGY ANALYSIS METHODS WITH DISCUSSION}

\subsection{Calculation Results of HPT energy FLOW STREAM METHOD}

Calculation results of the energy flow stream method for all observed lost steam mass flow rate combinations (Table 2) are presented in Table 4

A decrease in steam mass flow rate lost through front gland seal resulted with an increase in the steam mass flow rate that expands through the HPT, which finally leads to an increase in the turbine real developed power at each observed load.

The HPT energy power input represents an amount of energy, which is delivered by steam at the turbine inlet. For each turbine load, the energy power input is calculated using an equation (8). Regardless of the lost steam mass flow rate through gland seals distribution, at each turbine load, the steam mass flow rate and steam operating parameters (pressure and temperature) at the turbine inlet are the same, therefore, the energy power input remains constant and is equal to 1083.6 MW for the HPT load of $60 \%$, 1441.4 MW for HPT load of 80\% and 1858.6 MW for HPT full load (100\%).

The energy power output of the analyzed HPT increases during the increase in the steam mass flow rate, which expands through the turbine, which is a valid conclusion for each turbine load. Such occurrence can be easily explained by using equation (9) - the decrease in the steam mass flow rate lost through the front gland seal increases the turbine real developed power, which proportionally leads to an increase in the turbine energy power output (at each turbine load, other components of the equation (9) remain unchanged).

The energy power loss of the HPT decreases during the decrease in the steam mass flow rate lost through the front gland seal at each turbine load, this can be explained by using the last expression of equation
(14). The steam specific enthalpy at the HPT inlet $\left(h_{1}\right)$ is much higher than the steam specific enthalpy at the turbine outlet $\left(h_{4}\right)$, therefore, any decrease in the steam mass flow rate lost through the front gland seal (and the proportionaly increase in the steam mass flow rate lost through the rear gland seal) will lead to decrease in HPT energy power loss.

In the energy flow stream method, the equation (15) defines the change of the HPT energy efficiency for each observed load. An increase in the steam mass flow rate, which expands through the $\mathrm{HPT}$, results in an increase in the turbine real developed power (turbine real developed power is the numerator in equation (15)). The denominator of equation (15) is a constant for each turbine load, defined by data from Table1, so the increase in the HPT real developed power results with a simultaneous increase in the turbine energy efficiency.

From the comparison of different turbine loads, a conclusion can be made that the HPT average energy power loss increases with an increase in the turbine load - from 12.14 MW on average at the HPT load of $60 \%$, to $13.85 \mathrm{MW}$ on average at the HPT load of $80 \%$ and finally to $16.25 \mathrm{MW}$ on average at the HPT load of $100 \%$. The dominant reason for such HPT energy power loss trend is the increase in the steam mass flow rate lost through both gland seals during the increase in the turbine load, equation (14).

The increase in the HPT load also results in an increase in the average turbine energy efficiency - from $91.45 \%$ on average at the HPT load of $60 \%$, to $92.58 \%$ on average at the HPT load of $80 \%$ and finally to $92.66 \%$ on average at the HPT load of $100 \%$. Such occurrence can be explained by using the equation (15) where the HPT real developed power has a higher intensity of increase than the denominator during the increase in the turbine load. The increase in the HPT real developed power is proportional to the increase in the steam mass flow rate at the turbine inlet (and simultaneously with the increase in the steam mass flow rate, which will expand through the turbine) during the load increase.

The main conclusion, which can be derived from the results of the energy flow stream method is that this method is the most dependable on the steam mass flow rates (which expand through the turbine and get partially lost through both gland seals). The results obtained by the energy flow stream method are expected for the analysed HPT - an increase in the turbine load resulted with an increase in the turbine energy power loss and with an increase in the turbine energy efficiency.

\subsection{Calculation Results of HPT ISENTROPIC METHOD}

The calculation results of the isentropic method for all observed lost steam mass flow rate combinations (Table 2) are presented in Table 5 


\begin{tabular}{|c|c|c|c|c|c|}
\hline $\begin{array}{c}\text { Comb. } \\
\text { number } \\
\text { (Table } 2\end{array}$ & $\begin{array}{l}\text { Real } \\
\text { (poly.) } \\
\text { power } \\
\text { MW }\end{array}$ & $\begin{array}{c}\text { Energy } \\
\text { power } \\
\text { input } \\
\text { MW }\end{array}$ & $\begin{array}{c}\text { Energy } \\
\text { power } \\
\text { output } \\
\text { MW }\end{array}$ & $\begin{array}{c}\text { Energy } \\
\text { power } \\
\text { loss } \\
\text { MW }\end{array}$ & $\begin{array}{c}\begin{array}{c}\text { Energy } \\
\text { eff. }\end{array} \\
\%\end{array}$ \\
\hline \multicolumn{6}{|c|}{ HPT load $60 \%$} \\
\hline No.1 & 129.13 & 1083.6 & 1070.67 & 12.93 & 90.90 \\
\hline No.2 & 129.29 & 1083.6 & 1070.83 & 12.78 & 91.01 \\
\hline No.3 & 129.44 & 1083.6 & 1070.98 & 12.62 & 91.12 \\
\hline No.4 & 129.60 & 1083.6 & 1071.14 & 12.46 & 91.23 \\
\hline No. 5 & 129.76 & 1083.6 & 1071.30 & 12.30 & 91.34 \\
\hline No.6 & 129.92 & 1083.6 & 1071.46 & 12.14 & 91.45 \\
\hline No.7 & 130.08 & 1083.6 & 1071.62 & 11.99 & 91.56 \\
\hline No.8 & 130.23 & 1083.6 & 1071.77 & 11.83 & 91.67 \\
\hline No.9 & 130.39 & 1083.6 & 1071.93 & 11.67 & 91.78 \\
\hline No.10 & 130.55 & 1083.6 & 1072.09 & 11.51 & 91.90 \\
\hline No.11 & 130.71 & 1083.6 & 1072.25 & 11.36 & 92.01 \\
\hline \multicolumn{6}{|c|}{ HPT load $80 \%$} \\
\hline No.1 & 171.92 & 1441.4 & 1426.67 & 14.76 & 92.10 \\
\hline No.2 & 172.10 & 1441.4 & 1426.85 & 14.57 & 92.19 \\
\hline No.3 & 172.28 & 1441.4 & 1427.03 & 14.39 & 92.29 \\
\hline No.4 & 172.46 & 1441.4 & 1427.21 & 14.21 & 92.39 \\
\hline No. 5 & 172.64 & 1441.4 & 1427.39 & 14.03 & 92.48 \\
\hline No.6 & 172.83 & 1441.4 & 1427.57 & 13.85 & 92.58 \\
\hline No.7 & 173.01 & 1441.4 & 1427.75 & 13.67 & 92.68 \\
\hline No.8 & 173.19 & 1441.4 & 1427.93 & 13.49 & 92.77 \\
\hline No.9 & 173.37 & 1441.4 & 1428.11 & 13.31 & 92.87 \\
\hline No.10 & 173.55 & 1441.4 & 1428.29 & 13.13 & 92.96 \\
\hline No.11 & 173.73 & 1441.4 & 1428.47 & 12.95 & 93.06 \\
\hline \multicolumn{6}{|c|}{ HPT load $100 \%$} \\
\hline No.1 & 204.25 & 1858.6 & 1841.4 & 17.22 & 92.22 \\
\hline No.2 & 204.44 & 1858.6 & 1841.6 & 17.03 & 92.31 \\
\hline No.3 & 204.64 & 1858.6 & 1841.8 & 16.84 & 92.40 \\
\hline No.4 & 204.83 & 1858.6 & 1842.0 & 16.64 & 92.49 \\
\hline No. 5 & 205.03 & 1858.6 & 1842.2 & 16.45 & 92.57 \\
\hline No.6 & 205.22 & 1858.6 & 1842.4 & 16.25 & 92.66 \\
\hline No.7 & 205.41 & 1858.6 & 1842.6 & 16.06 & 92.75 \\
\hline No.8 & 205.61 & 1858.6 & 1842.8 & 15.86 & 92.84 \\
\hline No.9 & 205.80 & 1858.6 & 1843.0 & 15.67 & 92.93 \\
\hline No.10 & 206.00 & 1858.6 & 1843.2 & 15.47 & 93.01 \\
\hline No.11 & 206.19 & 1858.6 & 1843.4 & 15.28 & 93.10 \\
\hline
\end{tabular}

TABle 4. Calculation results of energy flow stream method. 
A decrease in the steam mass flow rate lost through the front gland seal simultaneously increases the steam mass flow rate, which expands through the HPT, which results in an increase in both real (polytropic) and ideal (isentropic) turbine power at each observed turbine load. For each HPT load and for each combination of steam mass flow rate lost through both gland seals, the real developed turbine power is calculated according to equation (5), while an ideal turbine power is calculated by using an equation (17). The same increase in the steam mass flow rate which expands through the HPT will result in a more intensive increase in the turbine ideal than real developed power, because steam specific enthalpy differences in equation (17) are higher than in equation (5).

In the isentropic energy analysis method, more intensive increase in the HPT ideal power, in comparison with the real power during the increase in the steam mass flow rate, which expands through the turbine, will result in an increase in the energy power loss, equation (18), which is a valid conclusion for each observed turbine load. However, a change in the steam mass flow rate, which expands through the HPT, has a negligible influence on the turbine energy efficiency while using the isentropic energy analysis method, at any observed turbine load.

It can be seen from Table 5 that the change in the steam mass flow rate, which expands through the analysed HPT, results in a very small change in the turbine energy power loss and in a negligible change in the turbine energy efficiency while using the isentropic method. Therefore, it can be concluded that the change in the steam mass flow rate, which expands through the HPT, at any load is not the dominant element, which defines the turbine energy losses and energy efficiencies in the isentropic energy analysis method.

When comparing different HPT loads by the isentropic energy analysis method, it can be concluded that the turbine average energy power loss increases with an increase in the turbine load - from 3.417 MW on average at the HPT load of $60 \%$, to $5.611 \mathrm{MW}$ on average at the HPT load of $80 \%$, and finally, a significant increase can be noted at the HPT load of $100 \%$ (22.943 MW on average).

In the isentropic method, an increase in the HPT load resulted with a continuous decrease of the turbine energy efficiency. An increase in the HPT load from $60 \%$ to $80 \%$ resulted in a small decrease in the turbine energy efficiency - from $97.437 \%$ to $96.855 \%$. A further increase in the HPT load from $80 \%$ to $100 \%$ resulted with a significant decrease in the turbine energy efficiency - from $96.855 \%$ to $89.944 \%$.

The results obtained by the isentropic energy analysis method show an unexpected HPT behaviour during increase in turbine load - the HPT average energy power loss significantly increases at a full turbine load, while the energy efficiency continuously decreases.
As it was proved before, the change in steam mass flow rate, which expands through the HPT, does not have a significant influence on the turbine energy power loss and energy efficiency in the isentropic method, at any observed load. The most dominant element in the applied isentropic method for the HPT (or any other steam turbine) energy analysis is a real (polytropic) steam expansion process and its comparison with an ideal (isentropic) steam expansion process. The higher difference of the polytropic steam expansion process from the isentropic steam expansion process will result in a higher energy power loss and, simultaneously, in a lower energy efficiency - this conclusion is valid for an energy analysis of any steam turbine while applying the isentropic method. The difference in steam expansion processes (ideal and real) can also be observed as a difference in steam specific enthalpies between polytropic and isentropic expansion processes (between two same steam pressures) - a higher difference in steam specific enthalpies will result in a higher energy power loss and lower energy efficiency of any steam turbine.

A plot of steam expansion processes for the analyzed HPT at each load, shown in Fig. 3. proves the above made conclusion. The real (polytropic) steam expansion process at the HPT load of $60 \%$ is the closest to an ideal (isentropic) steam expansion process - therefore, at the lowest observed load, the HPT will have the lowest energy power loss and the highest energy efficiency. At the HPT load of $80 \%$, the polytropic steam expansion process deviates from the isentropic expansion process a little more than during the HPT load of $60 \%$ - therefore, at the HPT load of $80 \%$, the analysed turbine will have a higher energy power loss and lower energy efficiency in comparison with the HPT load of $60 \%$.

Fig. 3 clearly presents that the polytropic steam expansion process significantly deviates from the isentropic steam expansion process at the HPT full load (load of 100\%). From such polytropic steam expansion process at the HPT load of 100\%, a much higher energy power loss and much lower energy efficiency of the analyzed turbine can be expected when compared to lower loads. The reason of such difference between polytropic and isentropic steam expansion processes at the HPT full load is exceeding the critical pressure at the HPT inlet (at the steam generator outlet, Fig. 1), as the analyzed turbine operates in a supercritical thermal power plant. The water/steam critical pressure, as noted in the fluid information of Nist REFPROP 9.0 software [57] is 220.64 bars. It can be seen from Table 1 that the critical pressure at the HPT inlet is exceeded only at the turbine load of $100 \%$. The exceeding of the critical pressure significantly influenced the HPT steam real (polytropic) expansion process (in comparison with polytropic steam expansion processes under the critical water/steam pressure). 


\begin{tabular}{|c|c|c|c|c|}
\hline $\begin{array}{c}\text { Comb. } \\
\text { number } \\
\text { (Table 2 }\end{array}$ & $\begin{array}{l}\text { Ideal } \\
\text { (isen.) } \\
\text { power } \\
\text { MW }\end{array}$ & $\begin{array}{c}\text { Real } \\
\text { (poly.) } \\
\text { power } \\
\text { MW }\end{array}$ & $\begin{array}{c}\text { Energy } \\
\text { power } \\
\text { loss } \\
\text { MW }\end{array}$ & $\begin{array}{c}\text { Energy } \\
\text { eff. } \\
\%\end{array}$ \\
\hline \multicolumn{5}{|c|}{ HPT load $60 \%$} \\
\hline No.1 & 132.53 & 129.13 & 3.396 & 97.437 \\
\hline No.2 & 132.69 & 129.29 & 3.400 & 97.437 \\
\hline No.3 & 132.85 & 129.44 & 3.405 & 97.437 \\
\hline No.4 & 133.01 & 129.60 & 3.409 & 97.437 \\
\hline No.5 & 133.17 & 129.76 & 3.413 & 97.437 \\
\hline No.6 & 133.34 & 129.92 & 3.417 & 97.437 \\
\hline No.7 & 133.50 & 130.08 & 3.422 & 97.437 \\
\hline No.8 & 133.66 & 130.23 & 3.426 & 97.436 \\
\hline No.9 & 133.82 & 130.39 & 3.430 & 97.436 \\
\hline No.10 & 133.98 & 130.55 & 3.434 & 97.436 \\
\hline No.11 & 134.15 & 130.71 & 3.439 & 97.436 \\
\hline \multicolumn{5}{|c|}{ HPT load $80 \%$} \\
\hline No.1 & 177.51 & 171.92 & 5.581 & 96.855 \\
\hline No.2 & 177.69 & 172.10 & 5.587 & 96.855 \\
\hline No.3 & 177.88 & 172.28 & 5.593 & 96.855 \\
\hline No.4 & 178.06 & 172.46 & 5.599 & 96.855 \\
\hline No. 5 & 178.25 & 172.64 & 5.605 & 96.855 \\
\hline No.6 & 178.44 & 172.83 & 5.611 & 96.855 \\
\hline No.7 & 178.62 & 173.01 & 5.617 & 96.855 \\
\hline No.8 & 178.81 & 173.19 & 5.623 & 96.855 \\
\hline No.9 & 178.99 & 173.37 & 5.629 & 96.855 \\
\hline No.10 & 179.18 & 173.55 & 5.635 & 96.855 \\
\hline No.11 & 179.37 & 173.73 & 5.641 & 96.855 \\
\hline \multicolumn{5}{|c|}{ HPT load $100 \%$} \\
\hline No.1 & 227.08 & 204.25 & 22.835 & 89.944 \\
\hline No. 2 & 227.30 & 204.44 & 22.857 & 89.944 \\
\hline No.3 & 227.51 & 204.64 & 22.878 & 89.944 \\
\hline No.4 & 227.73 & 204.83 & 22.900 & 89.944 \\
\hline No. 5 & 227.95 & 205.03 & 22.921 & 89.944 \\
\hline No.6 & 228.16 & 205.22 & 22.943 & 89.944 \\
\hline No.7 & 228.38 & 205.41 & 22.965 & 89.944 \\
\hline No.8 & 228.59 & 205.61 & 22.986 & 89.944 \\
\hline No.9 & 228.81 & 205.80 & 23.008 & 89.944 \\
\hline No.10 & 229.03 & 206.00 & 23.029 & 89.944 \\
\hline No.11 & 229.24 & 206.19 & 23.051 & 89.944 \\
\hline
\end{tabular}

TABLE 5. Calculation results of isentropic method. 


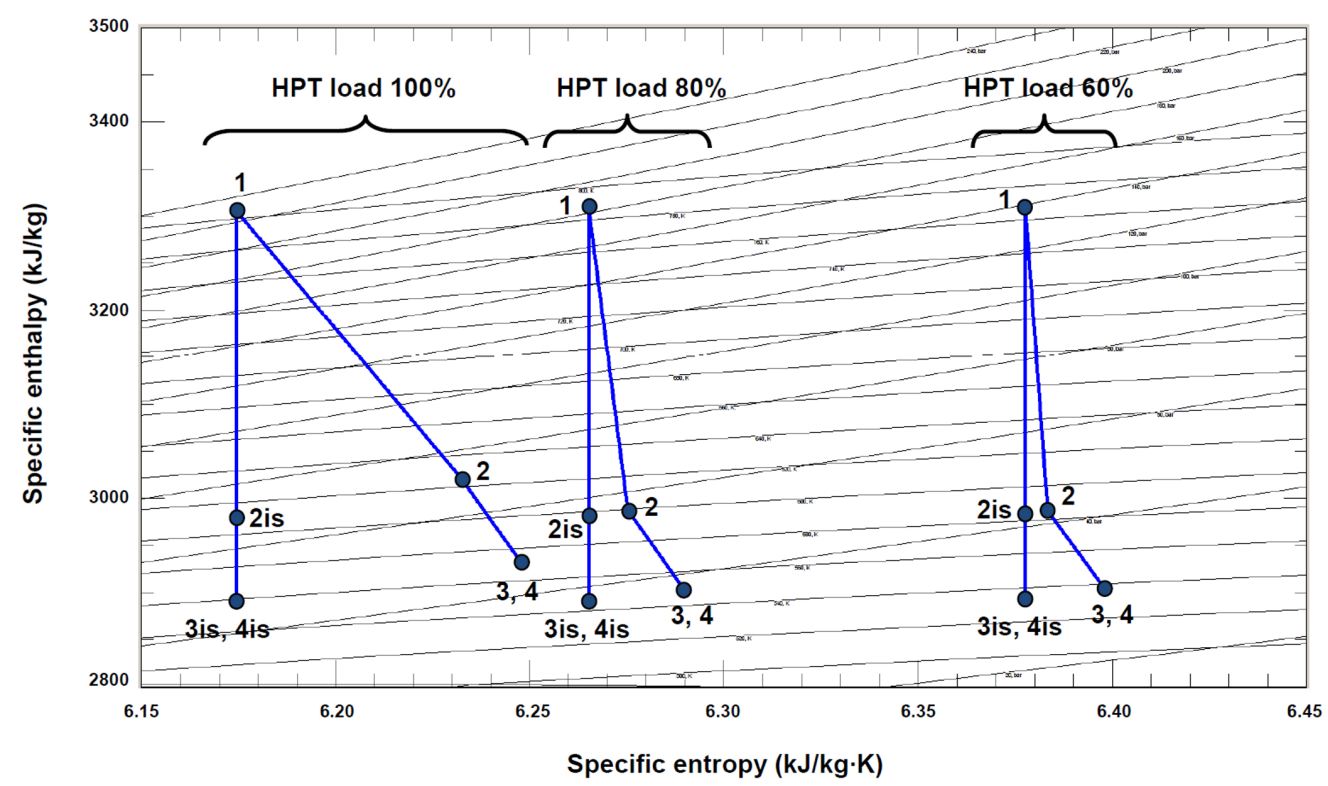

FiguRE 3. Differences between the HPT ideal (isentropic) and real (polytropic) steam expansion processes for each observed turbine load - plotted from Nist REFPROP 9.0 [57.

\section{Comparison OF ENERGy FLOW STREAM AND ISENTROPIC ENERGY ANALYSIS METHODS FOR RESEARCHED HPT}

In this section a direct comparison of the energy flow stream and isentropic methods for the HPT energy analysis are presented. Energy power losses and energy efficiencies of the analyzed HPT at each observed turbine load and for each observed combination of lost steam mass flow rate through both gland seals were compared.

At the HPT load of $60 \%$, the difference in the turbine energy power loss calculated by the energy flow stream method and isentropic method is between 7.92 MW and 9.54 MW, Fig. 4. An increase in the steam mass flow rate, which expands through the turbine, results in a decrease in the energy power loss difference between observed methods. At the same HPT load (load of $60 \%$ ), the difference in the turbine energy efficiency calculated by the isentropic method and the energy flow stream method is between $5.43 \%$ and $6.54 \%$, Fig. 4, while the increase in the steam mass flow rate, which expands through the turbine, results in a decrease in energy efficiency difference between observed methods (Table 4 and Table 5 ).

The same trends in differences of energy power loss and energy efficiency between the energy flow stream method and isentropic method are observed at the HPT load of $80 \%$, Fig. 5 The energy power loss difference between the energy flow stream method and isentropic method at the HPT load of $80 \%$ is between 7.31 MW and 9.17 MW, while the difference in the turbine energy efficiency between the isentropic method and energy flow stream method is between $3.79 \%$ and $4.76 \%$, Fig. 5 An increase in the steam mass flow rate, which expands through the HPT, results in a decrease in both energy power loss difference and energy efficiency difference between the observed methods (Table 4 and Table 5) also at the HPT load of $80 \%$.

The trends in differences of the HPT energy power loss and energy efficiency between energy flow stream method and isentropic method are reversed at the HPT load of $100 \%$ when compared to lower turbine loads, Fig. 6. The reason of such occurrence can be found in the fact that at the HPT load of $100 \%$, the energy power loss of the analysed steam turbine calculated by the isentropic method is much higher than the energy power loss calculated by the energy flow stream method, while the turbine energy efficiency calculated by the isentropic method is lower than the energy efficiency calculated by the energy flow stream method, for each steam mass flow rate, which expands through the turbine (Table 4 and Table 5). Therefore, at the HPT load of $100 \%$, the energy power loss difference between the isentropic method and the energy flow stream method is between 5.61 MW and 7.77 MW, while the difference in the turbine energy efficiency between the energy flow stream method and the isentropic method is between $2.28 \%$ and $3.16 \%$, Fig. 6. At the HPT load of $100 \%$, an increase in the steam mass flow rate, which expands through the analysed turbine, results in an increase in the energy power loss difference and energy efficiency difference between observed methods.

When the observed HPT loads are compared, it can be concluded that the average differences in the turbine energy power loss and the energy efficiency between the energy flow stream method and isentropic method decreases during the increase in the turbine load. An increase in the HPT load results in a decrease 


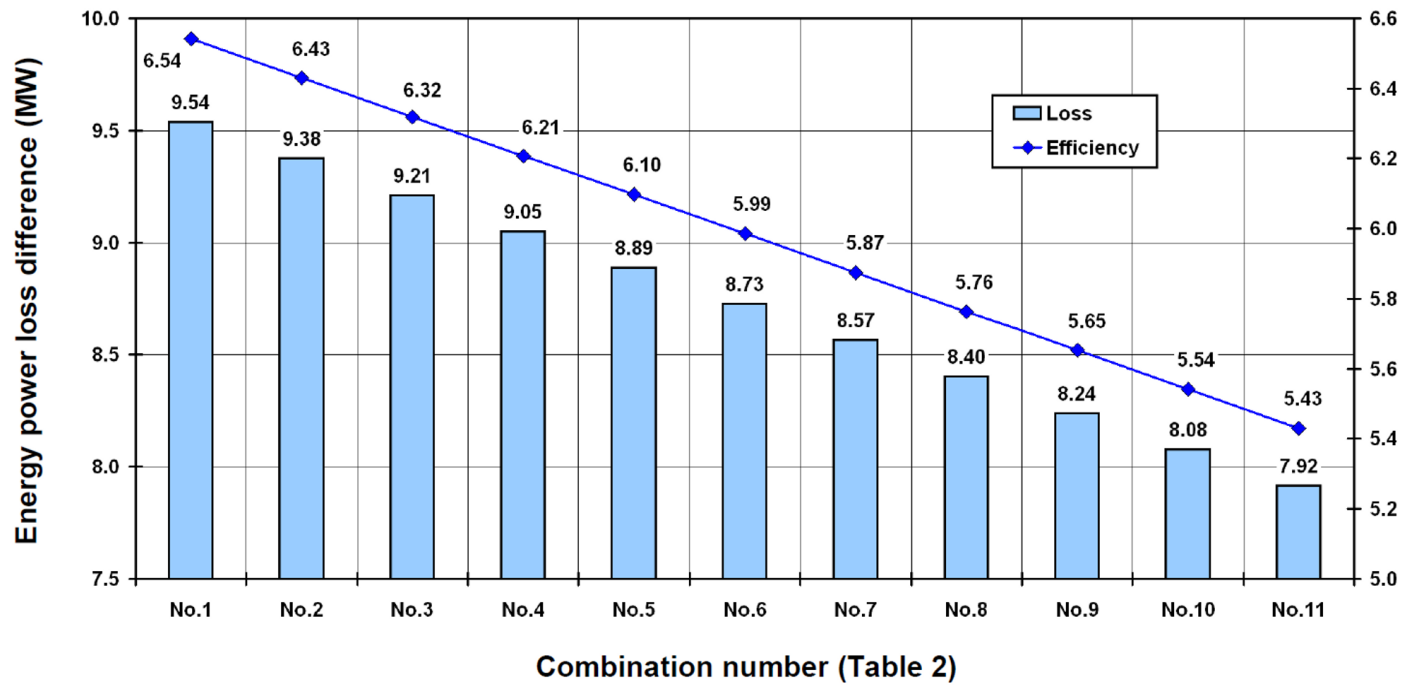

FiguRE 4. Comparison of energy flow stream method and isentropic method - difference in energy power loss and energy efficiency (HPT load of $60 \%$ ).

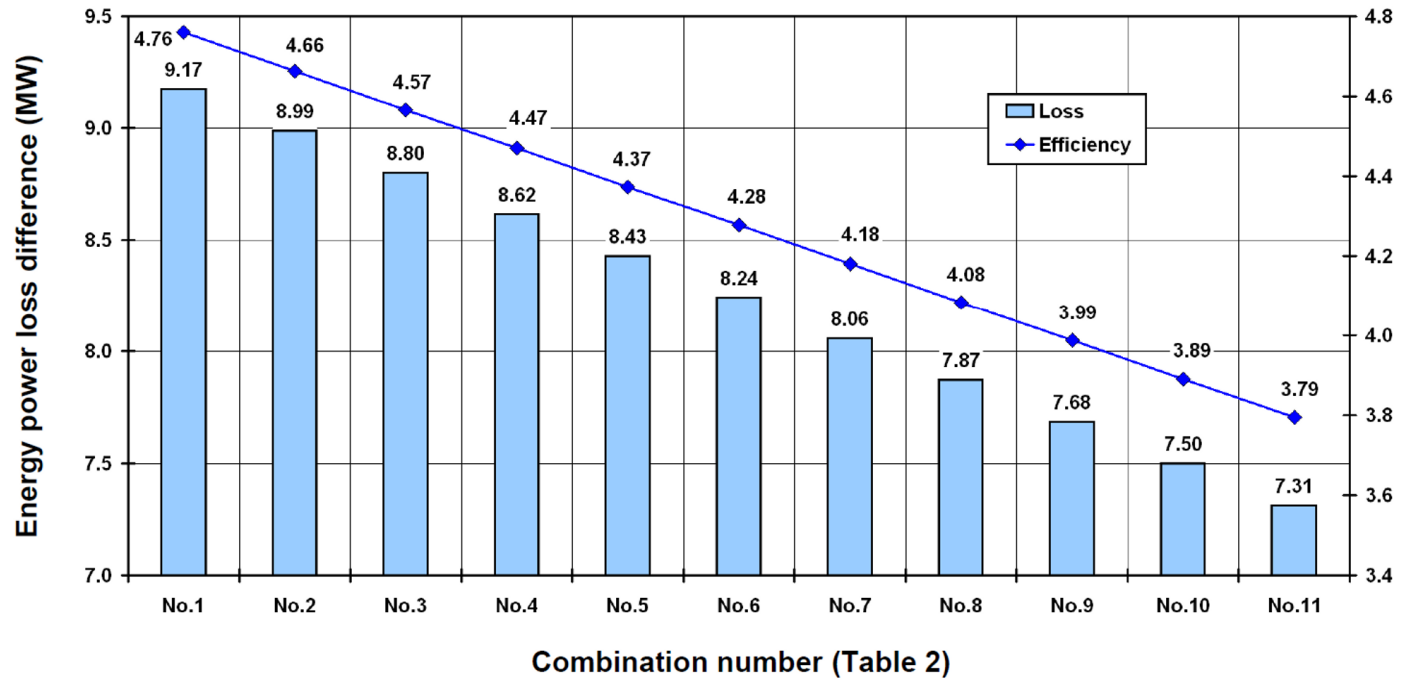

FIGURE 5. Comparison of energy flow stream method and isentropic method - difference in energy power loss and energy efficiency (HPT load of $80 \%$ ).

of the average energy power loss difference between the energy analysis methods from $8.73 \mathrm{MW}$ on average at the HPT load of $60 \%$, to $8.24 \mathrm{MW}$ on average at the HPT load of $80 \%$ and finally to $6.69 \mathrm{MW}$ on average at the HPT load of $100 \%$. In the same turbine load range, the average energy efficiency difference between the observed energy analysis methods decrease from $5.99 \%$ on average (load of $60 \%$ ) to $4.28 \%$ on average (load of $80 \%$ ) and finally to $2.72 \%$ on average (load of $100 \%$ ).

A direct comparison of the energy flow stream method and the isentropic method for the energy analysis of the HPT showed that these two methods cannot be directly compared. This conclusion is valid not just for the analysed, but also for any other steam turbine.

As presented for the HPT, the energy flow stream method and isentropic method cannot be directly com- pared because they present different steam turbine energy losses (and consequently different energy efficiencies). On the one hand the energy flow stream method presents steam turbine energy efficiencies and energy power losses which arise from the steam mass flow rates (which expand through the turbine and get partially lost through both turbine gland seals). The isentropic method, on the other hand, presents energy power losses and energy efficiencies, which arise from the steam real (polytropic) expansion process through the turbine and its comparison with the ideal (isentropic) steam expansion process. The change of steam mass flow rates (which expand through the turbine and lost one through both turbine gland seals) has almost a negligible influence on the results of the isentropic method, similarly, the comparison of steam expansion processes (ideal and real) has an almost negligible influence on the results of the energy flow 


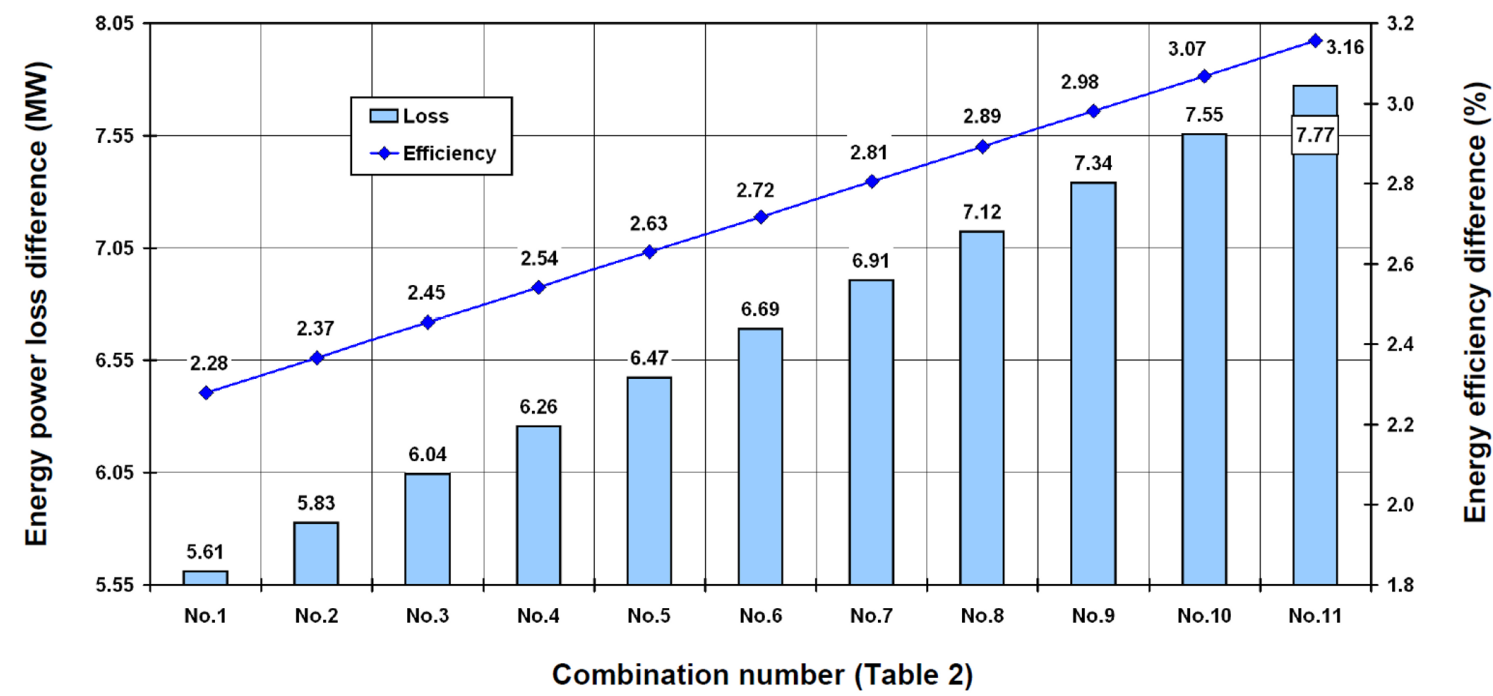

Figure 6. Comparison of energy flow stream method and isentropic method - difference in energy power loss and energy efficiency (HPT load of 100\%).

stream method - which is proved by the presented analysis of the HPT.

The question which arises from the presented comparison is - which method for the energy analysis of any steam turbine gives more reliable and more precise results and which can be used as the relevant one? The proper answer to this question is that a complete (overall) energy analysis of any steam turbine should be performed by using both of the presented methods. Combination of the steam turbine energy power losses and energy efficiencies obtained by both of these methods are relevant and such combination gives a better insight in the energy analysis of any steam turbine.

\section{The OVERALl HPT ENERGy ANALYSIS}

An overall energy analysis of the researched HPT (or any other steam turbine) incorporates energy power losses and energy efficiencies of both energy flow stream and isentropic methods. Both of these methods contribute to the overall HPT (or any other steam turbine) energy efficiency and energy power loss analysis. The overall energy power loss of the analyzed HPT is calculated as a sum of energy power losses obtained by the energy flow stream method and isentropic method:

$$
\dot{E}_{e n, P L, O V E R A L L}=\dot{E}_{e n, P L, E F S}+\dot{E}_{e n, P L, I S},
$$

while the overall energy efficiency of the analyzed HPT is calculated by multiplying the energy efficiencies obtained by the energy flow stream method and the isentropic method:

$$
\eta_{e n, O V E R A L L}=\eta_{e n, E F S} \cdot \eta_{e n, I S} .
$$

The change in the overall energy power loss of the analyzed HPT for each observed turbine load and for each observed steam mass flow rate, which expand through the turbine, is presented in Fig. 7.

When different HPT loads are compared, the lowest overall energy power loss can be seen at the lowest observed HPT load (load of 60\%) due to the lowest energy power losses calculated by both observed energy analysis methods (Table 4 and Table 5 with average value of $15.56 \mathrm{MW}$. The energy flow stream method and isentropic method give a slightly higher energy power losses at the HPT load of $80 \%$ (compared to the HPT load of $60 \%$ ), therefore, the overall energy power loss of the analyzed turbine at the load of $80 \%$ has an average value equal to $19.47 \mathrm{MW}$ (Table 4 and Table 5). A comparison of the highest observed HPT load (load of 100\%) with a lower HPT load (load of $80 \%$ ) shows that the overall turbine energy power loss significantly increase and its average value at the highest observed load is 39.20 MW. At the HPT load of $100 \%$, the energy flow stream method gives a higher (but not significantly) energy power loss when compared to lower turbine loads, while the isentropic method gives a significantly higher energy power loss when compared to lower turbine loads (Table 4 and Table 5). Such increase in the energy power loss of the isentropic method at the highest observed HPT load is caused by exceeding the critical water/steam pressure at the HPT inlet (polytropic steam expansion significantly deviates from the isentropic steam expansion (Fig. 4))

At each observed HPT load, increase in the steam mass flow rate, which expands through the turbine, results in a decrease in the overall turbine energy power loss due to the decrease of the HPT energy power loss calculated by the energy flow stream method (the same increase in the steam mass flow rate, which expands through the turbine, results in a small change in the energy power loss calculated by the isentropic method). The range of the overall HPT energy power 
loss during the increase in the steam mass flow rate, which expands through the turbine, is between 14.79 MW and 16.33 MW at the HPT load of $60 \%$, between 18.59 MW and 20.34 MW at the HPT load of $80 \%$, and, finally, between $38.33 \mathrm{MW}$ and $40.06 \mathrm{MW}$ at the HPT load of $100 \%$.

The change in the analysed HPT's overall energy efficiency for each observed turbine load and for each observed steam mass flow rate, which expands through the turbine, is presented in Fig. 8

A comparison of different HPT loads shows that the lowest overall energy efficiency is obtained at the highest observed HPT load (load of 100\%), which is caused by exceeding the critical water/steam pressure at the HPT inlet and a high deviation of the polytropic steam expansion process from the isentropic steam expansion process - the result is that the isentropic method gives a much lower HPT energy efficiency when compared to the lower turbine loads (regardless of the highest energy efficiency obtained with the energy flow stream method at the same HPT load). The average overall energy efficiency of the HPT at a load of $100 \%$ is $83.34 \%$. The analysed HPT, at a load of $60 \%$, has a much higher overall energy efficiency when compared to the highest observed turbine load - at a load of $60 \%$, the HPT has an average overall energy efficiency equal to $89.11 \%$, Fig. 8, due to the highest energy efficiency obtained by the isentropic method (when compared to other HPT loads).

The highest HPT average overall energy efficiency is obtained at the HPT load of $80 \%$ and is equal to $89.67 \%$. The reason of such occurrence can be found in comparison of the analysed turbine energy efficiency obtained by both observed energy analysis methods at a load of $60 \%$ and at a load of $80 \%$. The energy flow stream method gives higher HPT energy efficiencies at a turbine load of $80 \%$ in comparison with turbine load of $60 \%$, while the isentropic method resulted in a reversed conclusion (the energy efficiency of the HPT obtained by the isentropic method is higher at a load of $60 \%$, in comparison with a load of $80 \%$ ). The difference in the HPT's energy efficiency between the load of $60 \%$ and the load of $80 \%$ is higher for the energy flow stream method, therefore, the equation (21) results in higher values of the overall energy efficiency for the load of $80 \%$ than for the load of $60 \%$.

The increase in the steam mass flow rate, which expands through the analyzed turbine, results in an increase in the turbine's overall energy efficiency, which is a valid conclusion for each observed HPT load, Fig. 8. The reason of such occurrence is found in the following fact - the increase in the steam mass flow rate, which expands through the turbine, increases the HPT energy efficiency calculated by the energy flow stream method, while the same increase in the steam mass flow rate, which expands through the turbine, results in a negligible change in the turbine energy efficiency calculated by the isentropic method. The range of the overall HPT energy efficiency during the increase in the steam mass flow rate, which expands through the turbine, is between $82.95 \%$ and $83.74 \%$ at the HPT load of $100 \%$, between $88.57 \%$ and $89.65 \%$ at the HPT load of $60 \%$ and, finally, between $89.20 \%$ and $90.13 \%$ at the HPT load of $80 \%$.

\section{Conclusion}

In this paper, a comparison of two methods for a steam turbine energy analysis is presented. A high pressure steam turbine from a supercritical thermal power plant was analysed with both presented methods - the energy flow stream method and isentropic method, at three different turbine loads.

The energy flow stream method and its results are mostly influenced with two steam mass flow rates the first one is the steam mass flow rate, which expands through the HPT, and the second one is the cumulative steam mass flow rate lost through both HPT gland seals (and its distribution on the front and rear gland seal). The steam real (polytropic) expansion process throughout the turbine and its deviation from the ideal (isentropic) expansion process has a negligible influence on the energy flow stream method. For the analysed HPT, only the cumulative steam mass flow rate lost through both gland seals is known. As the steam mass flow rates lost through each (front and rear) gland seal are unknown, various combinations of the lost steam mass flow rate distribution are performed.

The isentropic energy analysis method and its results are mostly influenced by the real (polytropic) steam expansion process and its deviation from the ideal (isentropic) steam expansion process. For the analyzed HPT, this deviation is the highest at the highest observed turbine load (load of 100\%) due to exceeding a critical water/steam pressure. A steam mass flow rate, which expands through the analysed turbine, and the cumulative steam mass flow rate lost through both HPT gland seals has a very low influence on the HPT energy power loss and a negligible influence on the HPT energy efficiency calculated by using the isentropic energy analysis method.

The energy flow stream method and the isentropic energy analysis method of any steam turbine (not only the researched HPT) are not directly comparable because they are based on different sources of steam turbine energy losses (and consequently different energy efficiencies).

At the end of this paper, an overall steam turbine energy analysis, which involves energy efficiencies and energy losses of both methods for the steam turbine energy analysis, is presented. The change in energy power loss and energy efficiency of the HPT obtained by the overall energy analysis is:

- an increase of the HPT load (load of $60 \%, 80 \%$ and $100 \%$ ) results in an increase of the average overall HPT energy power loss (15.56 MW, 19.47 MW and 39.20 MW), 


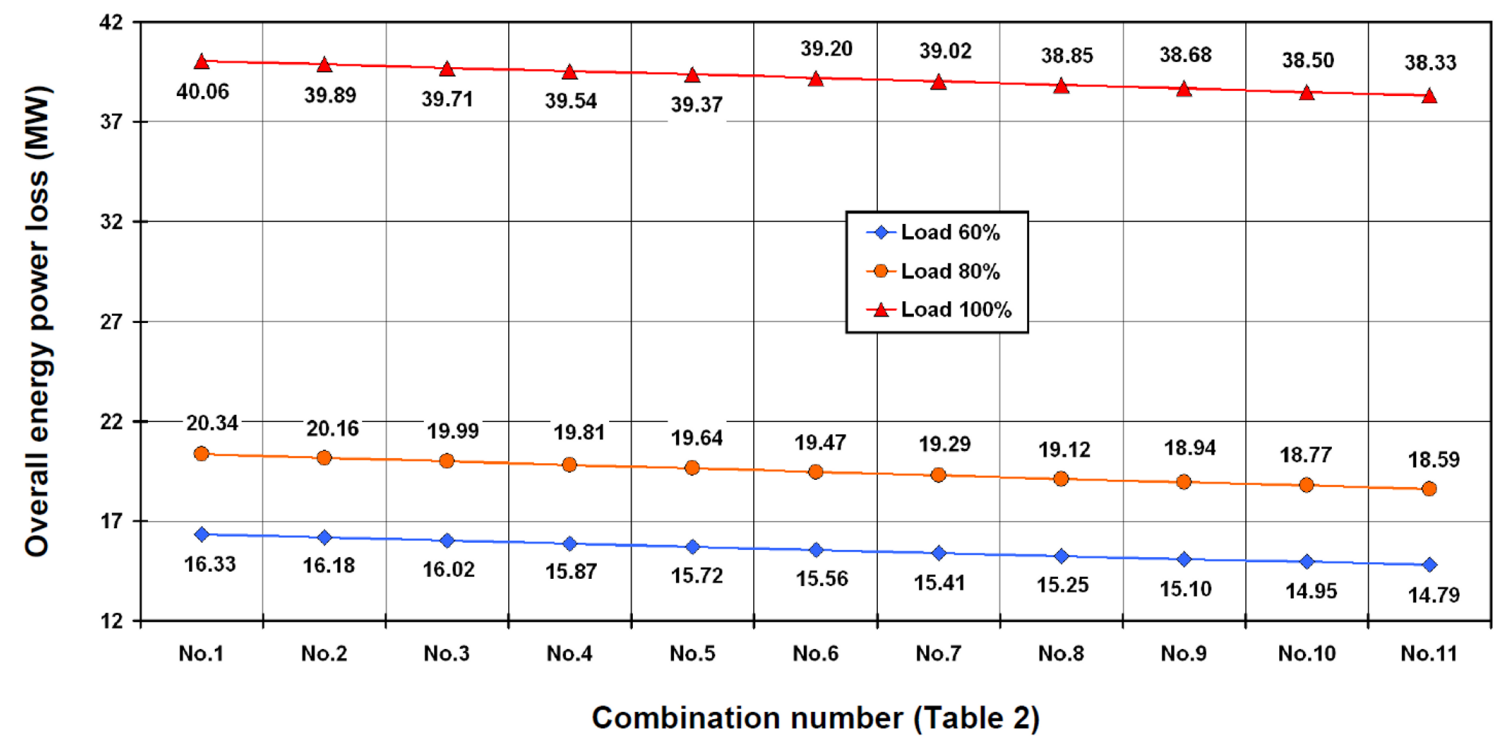

FiguRE 7. Overall energy power loss change of the analyzed HPT.

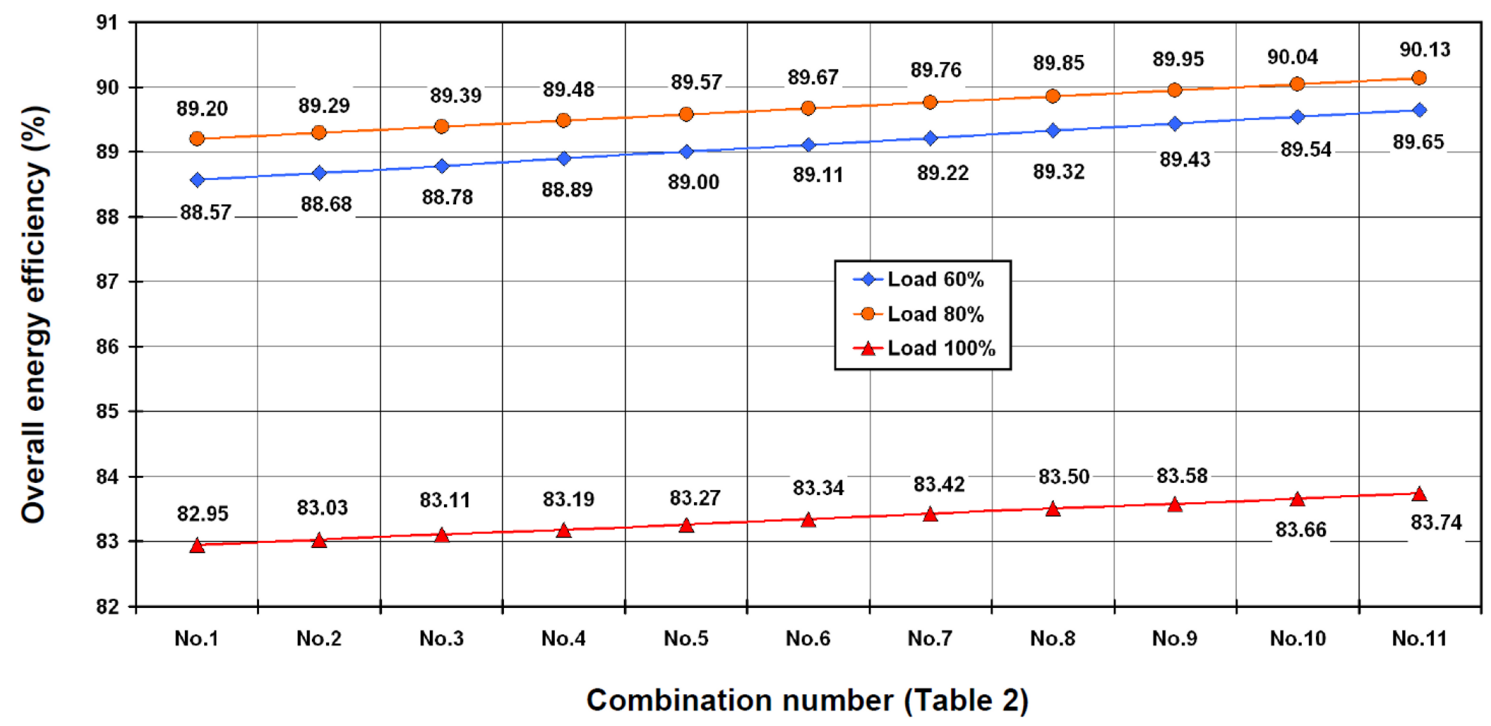

FiguRE 8. Overall energy efficiency change of the analyzed HPT.

- an increase of the steam mass flow rate, which expands throughout the HPT, at any load results in a decrease of the overall HPT energy power loss,

- the lowest HPT average overall energy efficiency $(83.34 \%)$ is obtained at a turbine load of $100 \%$ (full load). Such low average overall HPT energy efficiency at a full load is caused mostly because of exceeding a critical water/steam pressure,

- the highest HPT average overall energy efficiency $(89.67 \%)$ is obtained at a turbine load of $80 \%$, while at a turbine load of $60 \%$, the average overall energy efficiency is $89.11 \%$.

\section{LIST OF SYMBOLS}

\section{Latin Symbols:}

$\dot{E} \quad$ energy stream flow power $[\mathrm{kJ} / \mathrm{s}]$

$h$ specific enthalpy $[\mathrm{kJ} / \mathrm{kg}]$ $\dot{m}$ mass flow rate $[\mathrm{kg} / \mathrm{s}]$

$P$ power $[\mathrm{kJ} / \mathrm{s}]$

$\dot{Q}$ heat transfer $[\mathrm{kJ} / \mathrm{s}]$

$s \quad$ specific entropy $[\mathrm{kJ} /(\mathrm{kg} \mathrm{K})]$

\section{Greek Symbols:}

$\eta \quad$ efficiency

\section{Subscripts}

en energy

EFS energy flow stream (method)

$I N$ inlet (input)

$I S$ isentropic

OUT outlet (output)

$P L$ power loss

$R E$ real

\section{Abbreviations:}

HPT high pressure turbine 


\section{ACKNOWLEDGEMENTS}

This work has been fully supported by the Croatian Science Foundation under the project IP-2018-01-3739.

\section{REFERENCES}

[1] H. H. Erdem, A. Akkaya, B. Cetin, et al. Comparative energetic and exergetic performance analyses for coal-fired thermal power plants in Turkey. International Journal of Thermal Sciences 48:2179-2186, 2009. DOI:doi:10.1016/j.ijthermalsci.2009.03.007.

[2] D. Mitrović, D. Živković, M. S. Laković. Energy and exergy analysis of a $348.5 \mathrm{MW}$ steam power plant. Energy Sources, Part A 32:1016-1027, 2010. DOI:10.1080/15567030903097012

[3] R. Kumar, A. K. Sharma, T. P. C. Thermal performance and economic analysis of 210 MWe coal fired power plant. Journal of Thermodynamics 112:111-123, 2014. DOI:10.1155/2014/520183

[4] A. Noroozian, A. Mohammadi, M. Bidi, M. H. Ahmadi. Energy, exergy and economic analyses of a novel system to recover waste heat and water in steam power plants. Energy Conversion and Management 144:351-360, 2017. DOI:10.1016/j.enconman.2017.04.067

[5] G. R. Ahmadi, D. Toghraie. Energy and exergy analysis of Montazeri steam power plant in Iran. Renewable and Sustainable Energy Reviews 56:454-463, 2016. DOI:10.1016/j.rser.2015.11.074

[6] C. Uysal, H. Kurt, H. Y. Kwak. Exergetic and thermoeconomic analyses of a coal-fired power plant. International Journal of Thermal Sciences 117:106-120, 2017. DOI:10.1016/j.ijthermalsci.2017.03.010

[7] R. Kumar. Thermodynamic modeling and validation of a $210-\mathrm{MW}$ capacity coal-fired power plant. Iranian Journal of Science and Technology 40(3):233-242, 2016. DOI:10.1007/s40997-016-0025-5

[8] M. Naskar, S. Simlandi, N. Barman. An energy and exergy-based performance analysis and emission control of the turbine cycle in a coal-based steam power plant. Interdisciplinary Environmental Review 19(2):123-138, 2018. DOI:10.1504/IER.2018.093297

[9] V. Medica-Viola, B. Pavković, V. Mrzljak. Numerical model for on-condition monitoring of condenser in coal-fired power plants. International Journal of Heat and Mass Transfer 117:912-923, 2018. DOI:10.1016/j.ijheatmasstransfer.2017.10.047

[10] V. Mrzljak, J. Prpić-Oršić, T. Senčić. Change in steam generators main and auxiliary energy flow streams during the load increase of LNG carrier steam propulsion system. Scientific Journal of Maritime Research 32(1):121-131, 2018. DOI:10.31217/p.32.1.15

[11] H. Hajebzadeh, A. N. M. Ansari, S. Niazi. Mathematical modeling and validation of a $320 \mathrm{MW}$ tangentially fired boiler: A case study. Applied Thermal Engineering 146:232-242, 2019. DOI:10.1016/j.applthermaleng.2018.09.102

[12] J. Orović, V. Mrzljak, I. Poljak. Efficiency and losses analysis of steam air heater from marine steam propulsion plant. Energies 11(11):3019, 2018. DOI:10.3390/en11113019
[13] V. Mrzljak, I. Poljak, V. Medica-Viola.

Thermodynamical analysis of high-pressure feed water heater in steam propulsion system during exploitation. Shipbuilding: Theory and Practice of Naval Architecture, Marine Engineering and Ocean Engineering 68(2):45-61, 2017. DOI:10.21278/brod68204

[14] V. Mrzljak, I. Poljak, V. Medica-Viola. Energy and exergy efficiency analysis of sealing steam condenser in propulsion system of LNG carrier. Our Sea, International Journal of Maritime Science \& Technology 64(1):20-25, 2017. DOI:10.17818/NM/2017/1.4.

[15] V. Zare, M. Hasanzadeh. Energy and exergy analysis of a closed Brayton cycle-based combined cycle for solar power tower plants. Energy Conversion and Management 128:227-237, 2016. DOI:10.1016/j.enconman.2016.09.080.

[16] G. Ahmadi, D. Toghraie, O. Ali Akbari. Technical and environmental analysis of repowering the existing CHP system in a petrochemical plant: A case study. Energy 159:937-949, 2018. DOI:10.1016/j.energy.2018.06.208.

[17] M. H. Ahmadi, M. Ghazvini, M. Sadeghzadeh, et al. Solar power technology for electricity generation: A critical review. Energy Science \& Engineering pp. 1-22, 2018. DOI:10.1002/ese3.239

[18] G. Ahmadi, D. Toghraie, A. Azimian, O. A. Akbari. Evaluation of synchronous execution of full repowering and solar assisting in a $200 \mathrm{MW}$ steam power plant, a case study. Applied Thermal Engineering 112:111-123, 2016. DOI:10.1016/j.applthermaleng.2016.10.083.

[19] F. C. Eboh, P. Ahlström, T. Richards. Exergy analysis of solid fuel-fired heat and power plants: A review. Energies 10:165, 2017. DOI:10.3390/en10020165

[20] X. Zhang, H. Li, L. Liu, et al. Exergetic and exergoeconomic assessment of a novel CHP system integrating biomass partial gasification with ground source heat pump. Energy Conversion and Management 156:666-679, 2018. DOI:10.1016/j.enconman.2017.11.075

[21] M. H. Taheri, A. H. Mosaffa, L. Garousi Farshi. Energy, exergy and economic assessments of a novel integrated biomass based multigeneration energy system with hydrogen production and LNG regasification cycle. Energy 125:162-177, 2017. DOI:10.1016/j.energy.2017.02.124

[22] D. Li, J. Wang. Study of supercritical power plant integration with high temperature thermal energy storage for flexible operation. Journal of Energy Storage 20:140-152, 2018. DOI:10.1016/j.est.2018.09.008

[23] A. Naserbegi, M. Aghaie, A. Minuchehr, G. Alahyarizadeh. A novel exergy optimization of Bushehr nuclear power plant by gravitational search algorithm (GSA). Energy 148:373-385, 2018. DOI:10.1016/j.energy.2018.01.119

[24] T. Koroglu, O. S. Sogut. Conventional and advanced exergy analyses of a marine steam power plant. Energy 163:392-403, 2018. DOI:10.1016/j.energy.2018.08.119.

[25] T. Koroglu, O. S. Sogut. Advanced exergy analysis of an organic Rankine cycle waste heat recovery system of a marine power plant. Journal of Thermal Engineering 3(2):1136-1148, 2017. DOI:10.18186/thermal.298614 
[26] V. Mrzljak, I. Poljak, J. Prpić-Oršić. Exergy analysis of the main propulsion steam turbine from marine propulsion plant. Shipbuilding: Theory and Practice of Naval Architecture, Marine Engineering and Ocean Engineering 70(1):59-77, 2019. DOI:10.21278/brod70105

[27] V. Mrzljak, T. Senčić, B. Žarković. Turbogenerator steam turbine variation in developed power: Analysis of exergy efficiency and exergy destruction change. Modelling and Simulation in Engineering 2018, 2018. DOI:10.1155/2018/2945325

[28] F. Baldi, F. Ahlgren, T. Van Nguyen, et al. Energy and exergy analysis of a cruise ship. Energies 11(10):392-403, 2018. DOI:10.3390/en11102508.

[29] Y. Durmusoglu, G. Kocak. Exergetic efficiency analysis of a combined power plant of a container ship. Journal of Thermal Engineering 5(1):1-13, 2019. DOI:10.18186/thermal.467006

[30] F. Baldi, H. Johnson, C. Gabrielii, K. Andersson. Energy and exergy analysis of ship energy systems-the case study of a chemical tanker. International Journal of Thermodynamics 18(2):82-93, 2015. DOI:10.5541/ijot.70299

[31] T. Taner, M. Sivrioglu. Energy-exergy analysis and optimisation of a model sugar factory in Turkey. Energy 93:641-654, 2015. DOI:10.1016/j.energy.2015.09.007.

[32] N. Yildirim, S. Genc. Energy and exergy analysis of a milk powder production system. Energy Conversion and Management 149:698-705, 2017. DOI:10.1016/j.enconman.2017.01.064

[33] F. Bühler, T. Van Nguyen, J. Kjær Jensen, et al. Energy, exergy and advanced exergy analysis of a milk processing factory. Energy 162:576-592, 2018. DOI:10.1016/j.energy.2018.08.029

[34] M. J. Jokandan, M. Aghbashlo, S. S. Mohtasebi. Comprehensive exergy analysis of an industrial-scale yogurt production plant. Energy 93:1832-1851, 2015. DOI:10.1016/j.energy.2015.10.003.

[35] H. Tan, S. Shan, Y. Nie, Q. Zhao. A new boil-off gas re-liquefaction system for LNG carriers based on dual mixed refrigerant cycle. Cryogenics 92:84-92, 2018. DOI:10.1016/j.cryogenics.2018.04.009

[36] V. Mrzljak, I. Poljak, B. Žarković. Exergy analysis of steam pressure reduction valve in marine propulsion plant on conventional LNG carrier. Our Sea, International Journal of Maritime Science $\mathcal{E}$ Technology 64(1):24-31, 2018. DOI:10.17818/NM/2018/1.4.

[37] F. Cangioli, S. Chatterton, P. Pennacchi, et al. Thermo-elasto bulk-flow model for labyrinth seals in steam turbines. Tribology International 119:359-371, 2018. DOI:10.1016/j.triboint.2017.11.016.

[38] G. Ahmadi, D. Toghraie, O. Akbari. Energy, exergy and environmental (3E) analysis of the existing CHP system in a petrochemical plant. Renewable and Sustainable Energy Reviews 99:234-242, 2019. DOI:10.1016/j.rser.2018.10.009

[39] N. Akbari. Introducing and 3E (Energy, Exergy, Economic) analysis of an integrated transcritical CO2 Rankine cycle, Stirling power cycle and LNG regasification process. Applied Thermal Engineering 140:442-454, 2018. DOI:10.1016/j.applthermaleng.2018.05.073.
[40] S. Adibhatla, S. C. Kaushik. Energy, exergy, economic and environmental (4E) analyses of a conceptual solar aided coal fired 500 MWe thermal power plant with thermal energy storage option. Sustainable Energy Technologies and Assessments 21:89-99, 2017. DOI:10.1016/j.seta.2017.05.002

[41] M. Ameri, H. Mokhtari, M. Mostafavi Sani. 4E analyses and multi-objective optimization of different fuels application for a large combined cycle power plant. Energy 156:371-386, 2018. DOI:10.1016/j.energy.2018.05.039

[42] W. Chen, G. Zhang, B. Li, et al. Simulation study on $660 \mathrm{MW}$ coal-fired power plant coupled with a steam ejector to ensure NOx reduction ability. Applied Thermal Engineering 111:550-561, 2017. DOI:10.1016/j.applthermaleng.2016.09.104

[43] R. Kumar, R. Jilte, K. Chandrakant Nikam, M. H. Ahmadi. Status of carbon capture and storage in India's coal fired power plants: A critical review. Environmental Technology \& Innovation 13:94-103, 2019. DOI:10.1016/j.eti.2018.10.013.

[44] R. Kumar. A critical review on energy, exergy, exergoeconomic and economic (4-E) analysis of thermal power plants. Engineering Science and Technology, an International Journal 20(1):283-292, 2016. DOI:10.1016/j.jestch.2016.08.018.

[45] M. Ameri, P. Ahmadi, A. Hamidi. Energy, exergy and exergoeconomic analysis of a steam power plant: A case study. International Journal of Energy Research 33:499-512, 2009. DOI:10.1002/er.1495

[46] P. Šafařík, A. Nový, D. Jícha, M. Hajšman. On the speed of sound in steam. Acta Polytechnica 55(6):422-426, 2015. DOI:10.14311/APP.2015.55.0422

[47] S. Kumar, D. Kumar, R. A. Memon, et al. Energy and exergy analysis of a coal fired power plant. Mehran University Research Journal of Engineering $\& 3$ Technology 37(4):611-624, 2018. DOI:10.22581/muet1982.1804.13

[48] V. Mrzljak, I. Poljak, T. Mrakovčić. Energy and exergy analysis of the turbo-generators and steam turbine for the main feed water pump drive on LNG carrier. Energy Conversion and Management 140:307323, 2017. DOI:10.1016/j.enconman.2017.03.007.

[49] A. Colmenar-Santos, D. Gómez-Camazón, E. Rosales-Asensio, J.-J. Blanes-Peiró. Technological improvements in energetic efficiency and sustainability in existing combined-cycle gas turbine (CCGT) power plants. Applied Energy 223:30-51, 2018. DOI:10.1016/j.apenergy.2018.03.191

[50] V. Mrzljak. Low power steam turbine energy efficiency and losses during the developed power variation. Technical Journal 13(3):174-180, 2018. DOI:10.31803/tg-20180201002943

[51] R. Bet Sarkis, V. Zare. Proposal and analysis of two novel integrated configurations for hybrid solar biomass power generation systems: Thermodynamic and economic evaluation. Energy Conversion and Management 160:411-425, 2018. DOI:10.1016/j.enconman.2018.01.061 
[52] S. Adibhatla, S. C. Kaushik. Energy and exergy analysis of a super critical thermal power plant at various load conditions under constant and pure sliding pressure operation. Applied Thermal Engineering 73:4963, 2014. DOI:10.1016/j.applthermaleng.2014.07.030

[53] I. Poljak, J. Orović, V. Mrzljak. Energy and exergy analysis of the condensate pump during internal leakage from the marine steam propulsion system. Scientific Journal of Maritime Research 32(2):268-280, 2018. DOI: $10.31217 /$ p.32.2.12

[54] F. Hafdhi, T. Khir, A. Ben Yahyia, A. Ben Brahim. Energetic and exergetic analysis of a steam turbine power plant in an existing phosphoric acid factory. Energy Conversion and Management 106:1230-1241, 2015. DOI:10.1016/j.enconman.2015.10.044

[55] V. Mrzljak, I. Poljak, V. Medica-Viola. Dual fuel consumption and efficiency of marine steam generators for the propulsion of LNG carrier. Applied Thermal Engineering 119:331-346, 2017. DOI:10.1016/j.applthermaleng.2017.03.078
[56] M. Moran, H. Shapiro, D. D. Boettner, M. B. Bailey. Fundamentals of engineering thermodynamics, Seventh edition. John Wiley and Sons, Inc., 2011.

[57] E. W. Lemmon, M. L. Huber, M. O. McLinden. NIST Reference Fluid Thermodynamic and Transport Properties-REFPROP, Version 9.0, User's Guide. Colorado, 2010.

[58] A. Kostyuk, V. Frolov. Steam and gas turbines. Mir Publishers, 1988.

[59] S. N. Naserabad, A. Mehrpanahi, G. Ahmadi. Multi-objective optimization of HRSG configurations on the steam power plant repowering specifications. Energy 159:277-293, 2018. DOI:10.1016/j.energy.2018.06.130

[60] Z. Zhao, S. Su, N. Si, et al. Exergy analysis of the turbine system in a $1000 \mathrm{MW}$ double reheat ultra-supercritical power plant. Energy 119:540-548, 2017. DOI:10.1016/j.energy.2016.12.072 